\title{
Postmitotic Death Is the Fate of Constitutively Proliferating Cells in the Subependymal Layer of the Adult Mouse Brain
}

\author{
Cindi M. Morshead and Derek van der Kooy \\ Neurobiology Research Group, Department of Anatomy, University of Toronto, Toronto, Ontario, Canada M5S 1A8
}

The early development of the mammalian forebrain involves the massive proliferation of the ventricular zone cells lining the lateral ventricles. A remnant of this highly proliferative region persists into adult life, where it is known as the subependymal layer. We examined the proliferation kinetics and fates of the mitotically active cells in the subependyma of the adult mouse. The medial edge, the lateral edge, and the dorsolateral corner of the subependymal layer of the rostral portion of the lateral ventricle each contained mitotically active cells, but the dorsolateral region had the highest percentage of bromodeoxyuridine (BrdU)-labeled cells per unit area. Repeated injections of BrdU over $14 \mathrm{hr}$ revealed a proliferation curve for the dorsolateral population with a growth fraction of $33 \%$, indicating that $33 \%$ of the cells in this subependymal region make up the proliferating population. The total cell cycle time in this population was approximately $12.7 \mathrm{hr}$, with an S-phase of $\mathbf{4 . 2} \mathrm{hr}$. To examine the fate of these proliferating cells, we injected low concentrations of a replication-deficient, recombinant retrovirus directly into the lateral ventricles of adult mice for uptake by mitotically active subependymal cells. Regardless of the survival time postinjection ( $10 \mathrm{hr}, 1 \mathrm{~d}, 2 \mathrm{~d}$, or $8 \mathrm{~d}$ ), the number of retrovirally labeled cells per clone remained the same ( 1 or 2 cells/clone). This suggests that one of the progeny from each cell division dies. Moreover, the clones remained confined to the subependyma and labeled cells were not seen in the surrounding brain tissue. Thus, while $33 \%$ of the dorsolateral subependymal cells continue to proliferate in adult life, the fate of the postmitotic progeny is death.

Proliferation in the embryonic forebrain occurs in the ventricular zone, a region lining the ventricles that gives rise to postmitotic cells that migrate away from the ventricular zone and form the substance of the forebrain. Later in embryonic development, a second proliferative zone appears farther from the ventricular surface, called the subventricular zone. This region also gives rise to neurons and glia of the forebrain. Postnatally, the ventricular zone shrinks to a single layer called the ependyma. The subventricular zone persists into the adult as a mitotically active layer (several cells thick) known as the subependyma (Smart, 1961; Lewis, 1968; Privat and Leblond, 1972). This region of mitotic activity in the adult brain is particularly

\footnotetext{
Received July 10, 1991; accepted Aug. 26, 1991.

This work was supported by the Canadian Networks of Centres of Excellence.

Correspondence should be addressed to Cindi M. Morshead, Neurobiology Research Group, Department of Anatomy, University of Toronto, Toronto, Ontario M5S 1A8, Canada.

Copyright (C) 1992 Society for Neuroscience $0270-6474 / 92 / 120249-08 \$ 05.00 / 0$
}

curious, because neither the identity of the dividing cells nor the subsequent fate of the newly formed progeny are definitively known. In normal control animals it has been suggested that these cells migrate out into the adult forebrain to form neuroglia or even neurons (Altman, 1966, 1969; Privat and Leblond, 1972; Paterson et al., 1973). These suggestions were based on experiments labeling proliferating cells in the adult brain with tritiated thymidine ( ${ }^{3} \mathrm{H}$-thy) and the subsequent localization of labeled cells outside of the subependymal layer. Perhaps the subependymal population provides a reserve of cells that at times of stress participates in the large proliferative response seen at sites of injury in the brain (Morshead and van der Kooy, 1990). To examine the fate of adult subependymal cells, we utilized a replication-deficient, recombinant retrovirus to label the mitotically active cells and then looked for the migration of the labeled progeny out of the subependyma and into the surrounding brain tissue. Retroviral labeling permits unequivocal tracing of the progeny of an infected proliferating cell without dilution of the label.

${ }^{3} \mathrm{H}$-thy and bromodeoxyuridine (BrdU; a thymidine analog) can be used to investigate the cell cycle kinetics of anatomically defined populations in pre- and postnatal animals (Waechter and Jaensch, 1972; Korr et al., 1973; Lewis et al., 1977; Nowakowski et al., 1989). We utilized BrdU in a cumulative labeling protocol to determine the proliferation kinetics of the subependymal cells: (1) the length of the cell cycle $\left(T_{c}\right)$ and the DNA-synthetic phase $\left(T_{\mathrm{s}}\right)$ and (2) the growth fraction (GF), which is the proportion of subependymal cells that comprises the proliferating population. The combination of retroviral lineage tracing and BrdU labeling allowed us to conclude that the proliferating cells of the subependyma divide in a stem-cell mode with one postmitotic cell from each division dying.

\section{Materials and Methods}

Quantification of the proliferative response. Adult male CD1 mice (25$30 \mathrm{gm}$ ) were obtained from Charles River. To study the variation in the baseline proliferative response in the subependyma, in an initial experiment animals were divided into a control group $(n=4)$ and an expcrimental "stresscd" group $(n=5)$. Both groups werc injected intraperitoneally with physiological saline $(0.15 \mathrm{ml})$ for $7 \mathrm{~d}$. On the test day (day 8), the control group again received the saline solution while the experimental group received an intraperitoneal injection of sodium pentobarbital $(65 \mathrm{mg} / \mathrm{kg})$. On day 9 , both groups of animals were given intraperitoneal injections of $5 \mu \mathrm{Ci} / \mathrm{gm}{ }^{3} \mathrm{H}$-thy in order to label proliferating cells. The animals were killed $4 \mathrm{hr}$ post- ${ }^{3} \mathrm{H}$-thy with an overdose of sodium pentobarbital and transcardially perfused with $75-100 \mathrm{ml}$ of 4\% paraformaldehyde in $0.1 \mathrm{~m}$ phosphate buffer. The brains were removed, placed in $15 \%$ sucrose, and stored at $4^{\circ} \mathrm{C}$. Coronal sections, 32 $\mu \mathrm{m}$ thick, through the rostral forebrain were cut on a cryostat $\left(-14^{\circ} \mathrm{C}\right)$. Sections were mounted on gelled microscope slides, defatted, and then rehydrated in decreasing concentrations of ethyl alcohol and processed 


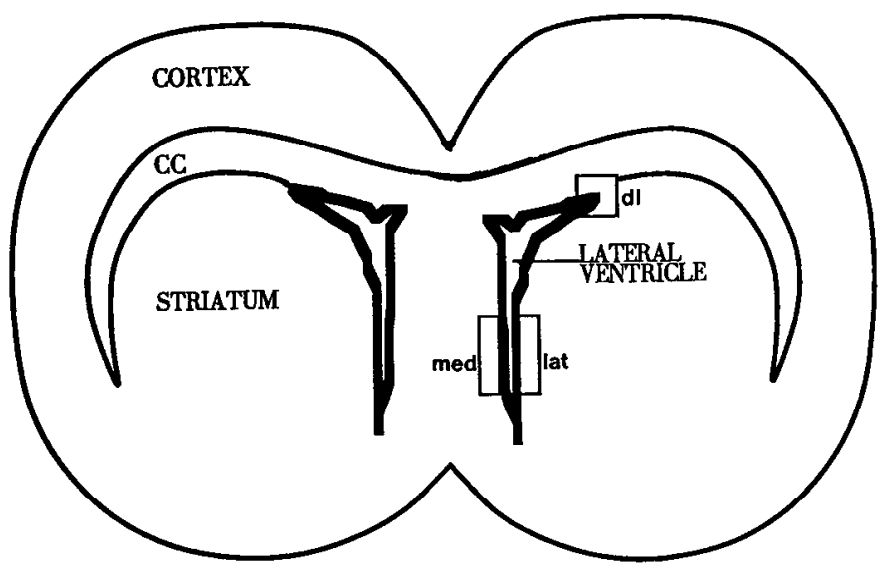

Figure 1. Schematic representation of a coronal section through the forebrain of an adult mouse showing the lateral ventricles and the subependymal layer lining them. The subependyma is divided into threc regions, the dorsolateral area $(d l)$, the lateral edge (lat), and the medial edge $(m e d)$. The boxed areas show the portion of each region from which counts of proliferating cells were made. These areas have varying mitotic activity, with the dorsolateral area being the most active, followed by the lateral area and then by the medial area. $C C$, corpus callosum.

for autoradiography by dipping the slides in liquid emulsion (Kodak NTB-2 nuclear track emulsion). The slides were exposed for approximately 2 months, after which time they were developed with Kodak D-19 developer and Nissl counterstained. A cell was considered labeled if there were five times more silver grains over the cell than over a comparable size area of non-perikaryal surrounding neuropil. The number of labeled subependymal cells surrounding the ventricle, in sections between the caudal portion of the genu of the corpus callosum and the crossing of the anterior commissure, were averaged from two sections (three to seven $350 \mu \mathrm{m}^{2}$ fields were counted per section) per animal and expressed per $350 \mu \mathrm{m}^{2}$.

Nissl-stained cells were counted by focusing through the tissue in the same regions as defined above. The total numbers of cells were averaged from two sections per animal and expressed per $350 \mu \mathrm{m}^{2}$.

Cumulative labeling with $\mathrm{BrdU}$ to determine proliferation kinetics. In order to label the entire population of proliferating subependymal cells, adult animals were injected with $\mathrm{BrdU}(65 \mathrm{mg} / \mathrm{kg}$, dissolved in 0.007 $N \mathrm{NaOH}$ in $0.9 \% \mathrm{NaCl}$ ) every hour for $14 \mathrm{hr}$. BrdU is a thymidine analog that is incorporated into the DNA of dividing cells during S-phase and can be visualized by immunocytochemistry. Animals were killed each hour, $0.5 \mathrm{hr}$ after each of the BrdU injections. A total of at least four animals were killed at each time point by anesthetic overdose and transcardially perfused with $4 \%$ paraformaldehyde as described above. The brains were removed and kept overnight in $15 \%$ sucrose at $4^{\circ} \mathrm{C}$. Sections $(32 \mu \mathrm{m})$ were cut on a cryostat at $-14^{\circ} \mathrm{C}$ and collected in $0.1 \mathrm{~m}$ PBS $\left(4^{\circ} \mathrm{C}\right)$. The sections were incubated in $1 \mathrm{M} \mathrm{HCl}$ for $30 \mathrm{~min}$ at $60^{\circ} \mathrm{C}$ to denature the DNA. This was followed by $3 \times 10 \mathrm{~min}$ washes with the washing solution ( $0.1 \mathrm{M}$ PBS containing $1 \%$ normal horse serum and $0.3 \%$ Triton $X-100$ ). The sections were subsequently incubated for $48 \mathrm{hr}\left(4^{\circ} \mathrm{C}\right)$ in a primary monoclonal antibody $(1: 25)$ directed against single-stranded DNA containing BrdU (Becton-Dickinson). After three washes, the sections were incubated in a biotinylated horse anti-mouse IgG (Cappel), at 1:50, for $1 \mathrm{hr}$ at room temperature. After three washes, the sections were incubated in avidin-conjugated fluorescein isothiocyanate (FITC; 1:50 dilution; Cappel). Following another three washes, the sections were mounted onto gelled slides and coverslipped with glycerol : water (10:1). BrdU-immunoreactive cells were examined under a fluorescence microscope with $470 \mathrm{~nm}$ wavelength illumination. Immunoreactive cells were counted in the dorsolateral regions of sections extending from the most caudal portion of the genu of the corpus callosum to the level of the crossing of the anterior commissure. The counts were averaged from the dorsolateral regions of two sections per animal, with a minimum of four animals per time point, and expressed as the mean number of BrdU-labeled cells per $350 \mu \mathrm{m}^{2}$.

Another group of animals received five injections (one every hour) of $\mathrm{BrdU}(65 \mathrm{mg} / \mathrm{kg})$ in an attempt to label some subependymal cells heavily for the entire S-phase $(4.2 \mathrm{hr})$, and the animals were then killed
2 or $8 \mathrm{~d}$ later. Sections from the same region as described above were examined. By looking for cells that remained labeled after $8 \mathrm{~d}$ we could discern whether the proliferating cells remained quiescent after mitosis or whether the population continued to divide.

A separate group of animals received a single injection of $\mathrm{BrdU}(65$ $\mathrm{mg} / \mathrm{kg}$, i.p.) and were killed $0.5 \mathrm{hr}$ later, in order to quantify the comparative numbers of cells proliferating in each of the medial edge, the lateral edge, and the dorsolateral corner of the lateral ventricle (Fig. 1). The number of BrdU-labeled cells in each of the dorsolateral, lateral, and medial areas was counted in two sections from each of four animals.

Retroviral injections. To examine the fate of the mitotically active adult cells, individual proliferating subependymal cells were infected with a retroviral marker that incorporates into DNA and replicates without dilution into all the progeny of the originally infected cell. Lineage analysis by the retroviral method depends on the identification of particular groups of lacZ-positive cells as descendants from a single infected progenitor. For this reason, subependymal cells were exposed to limiting dilutions of the retrovirus (as determined in pilot studies), thus infecting only one or a small number of proliferating cells per mouse. Retrovirus was harvested from the BAG cell line (ATCC CRL-9560) and concentrated using the method of Walsh and Cepko (1988). Adult CD1 mice were anesthetized using sodium pentobarbital $(65 \mathrm{mg} / \mathrm{kg}$, i.p. $)$, and unilateral stereotaxic injections of $0.4 \mu \mathrm{l}$ of recombinant retrovirus were made into the lateral ventricle using a $1 \mu 1$ Hamilton syringe. The coordinates for the injection were AP $+4 \mathrm{~mm}$ anterior to lambda, $\mathrm{L} \pm 1.9$ $\mathrm{mm}$, and DV $-2.5 \mathrm{~mm}$ below the dura, with the mouth bar at $-2 \mathrm{~mm}$ below the interaural line. The animals were killed $10 \mathrm{hr}(n=7), 1 \mathrm{~d}(n$ $=6), 2 \mathrm{~d}(n=10)$, or $8 \mathrm{~d}(n=9)$ after the retrovirus injection by anesthetic overdose and transcardially perfused with $2 \%$ paraformaldehyde in $0.1 \mathrm{M}$ phosphate buffer. The brains were removed and fixed overnight in $20 \%$ sucrose. Serial sections were cut at $56 \mu \mathrm{m}$ on a cryostat $\left(-14^{\circ} \mathrm{C}\right)$ and mounted directly onto gelled slides. The slides were stained for lacZ at $37^{\circ} \mathrm{C}$ overnight in the dark in a solution containing 5-bromo4-chloro-3-indolyl $\beta$-D-galactoside (X-gal; Promega) at $1 \mathrm{mg} / \mathrm{ml}, 20 \mathrm{nM}$ potassium ferrocyanide, $20 \mathrm{~mm}$ potassium ferricyanide, and $2 \mathrm{mM} \mathrm{MgCl}$ in phosphate-buffered saline. Before visualizing the lacZ reaction product, the slides were rinsed in $3 \%$ dimethyl sulfoxide in $0.1 \mathrm{M}$ PBS for 5 $\mathrm{min}$, followed by $3 \times 1 \mathrm{~min}$ rinses in $0.1 \mathrm{M}$ PBS. Slides were coverslipped with glycerol : water (10:1). In each mouse, the lacZ-positive cells were localized and counted in serial sections from the rostral genu of the corpus callosum extending caudally to the start of the third ventricle.

\section{Results}

\section{Stress causes an increase in the number of proliferating cells}

Animals that were injected with ${ }^{3} \mathrm{H}$-thy and then killed $4 \mathrm{hr}$ later demonstrated labeled cells in the subependymal layer surrounding the lateral ventricles in the forebrain (Fig. 2). There were very few cells proliferating in the forebrain outside of the subependyma. Rarely, proliferating endothelial cells were observed. There was a rostrocaudal gradient with respect to the number of proliferating cells, such that the more rostral sections contained more labeled cells (Smart, 1961; Altman, 1963). In the more caudal sections there was a decrease in the number of labeled cells, and at the rostral portion of the third ventricle virtually no labeled subependymal cells were seen.

Animals that were stressed by administering anesthetic $24 \mathrm{hr}$ earlier had more than three times as many ${ }^{3} \mathrm{H}$-thy-labeled subependymal cells than controls (Fig. $3 A$ ), when comparing the mean number of labeled cells surrounding the ventricles (controls, $0.26 \pm 0.06$ cells $/ 350 \mu \mathrm{m}^{2}, n=4$, vs. stress, $0.83 \pm 0.07 /$ $\left.350 \mu \mathrm{m}^{2}, n=5 ; t_{7}=6.86 ; p<0.05\right)$. This increase in the proliferating population was seen using other anesthetics (such as ether) as well as stress by food deprivation (data not shown). Our control group was handled and injected with saline for $7 \mathrm{~d}$ in an attempt to minimize the stress associated with an injection. Although we did observe a significant difference in the number of proliferating cells between our control and stressed groups, the control results may not reflect a true resting baseline. There was no significant difference in the average number of Nissl- 


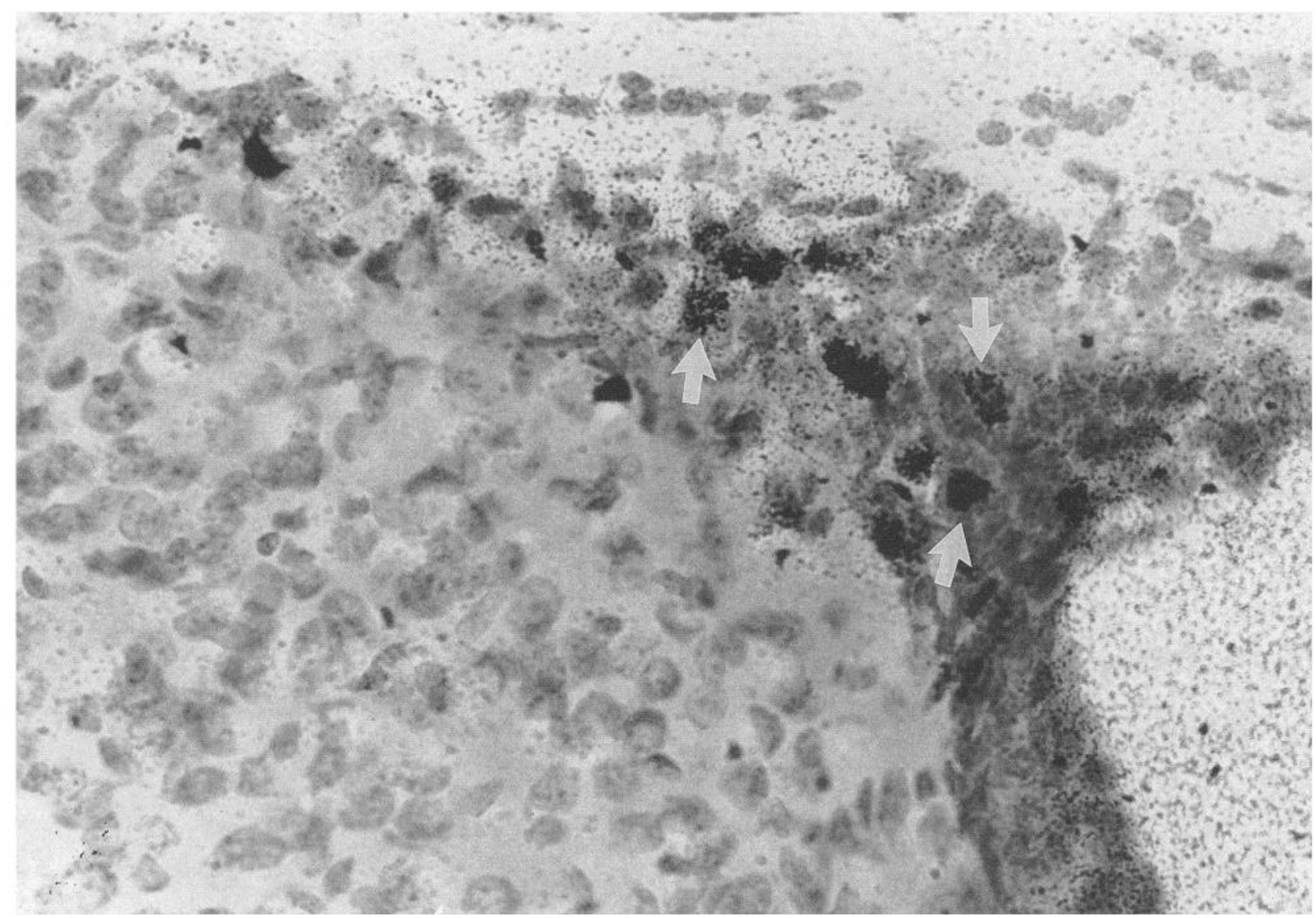

Figure 2. Bright-field photomicrograph of the dorsolateral area of the lateral ventricle with ${ }^{3} \mathrm{H}$-thy-marked subependymal cells (examples are arrowed), labeled after a single intraperitoneal injection of ${ }^{3} \mathrm{H}$-thy $4 \mathrm{hr}$ earlier.

stained cells per unit area between stressed versus control animals (Fig. $3 B$ ) (control, $15.52 \pm 3.55$ cells $/ 350 \mu \mathrm{m}^{2}, n=4$, vs. stress, $15.07 \pm 1.73$ cells $\left./ 350 \mu \mathrm{m}^{2}, n=5 ; t_{7}=0.20 ; p>0.05\right)$. Thus, stress appeared to be increasing the number of ${ }^{3} \mathrm{H}$-thylabeled cells and not the total number of Nissl-stained cells.

The subependyma was not homogeneous with respect to the number of proliferating cells surrounding the ventricle in sections at any given rostrocaudal level. We divided the subependymal layer into three regions in coronal sections, the dorsolateral corner, the lateral edge, and the medial edge (Fig. 1). One-half hour after a single BrdU injection, the dorsolateral area demonstrated the most BrdU-labeled cells per unit area, followed by the lateral and medial regions (dorsolateral, $2.18 \pm$ 0.69 cells $/ 350 \mu \mathrm{m}^{2}$; lateral, $0.71 \pm 0.13$ cells $/ 350 \mu \mathrm{m}^{2}$; medial, $0.34 \pm 0.18$ cells $\left./ 350 \mu \mathrm{m}^{2} ; n=4\right)$. The number of proliferating cells differed significantly over these three circumferential regions of the subependyma $\left(F_{2,6}=5.63 ; p<0.05\right)$. The dorsolateral region of the subependymal zone may be a remnant of the lateral migratory stream of the embryonic subventricular zone (Bayer et al., 1990). To test whether the regional heterogeneity was due to regional differences in total cell density, the total number of Nissl-stained cells per unit area in each of the dorsolateral, lateral, and medial areas was determined. These Nissl counts were taken from sections of the control brains from the first set of experiments. There was no significant difference $\left(F_{2,6}=0.155\right.$; $p>0.05$ ) among the three regions analyzed in the number of cells per unit area (dorsolateral, $14.12 \pm 1.40$ cells $/ 350 \mu \mathrm{m}^{2}$; lateral, $16.08 \pm 3.78$ cells $/ 350 \mu \mathrm{m}^{2}$; medial, $16.40 \pm 5.48$ cells/ $\left.350 \mu \mathrm{m}^{2} ; n=4\right)$. Hence, the regional variations in mitotic activity were not due to variations in the total number of cells in the subependyma. In general, BrdU labeling produced greater numbers of labeled cells than ${ }^{3} \mathrm{H}$-thy labeling, presumably due to the visualization of cells through the entire $32 \mu \mathrm{m}$ sections with BrdU immunoreactivity.

\section{Proliferation kinetics revealed by cumulative BrdU labeling}

After a series of BrdU injections into adult mice, the total counts were made of BrdU-labeled and unlabeled cells in the dorsolateral region of the subependyma (Figs. 4,5). Each injection of BrdU labels only those proliferating cells in the DNA synthetic phase (S-phase) during the time that BrdU is available for incorporation (Packard et al., 1973). Thus, the fraction of the proliferating population labeled at the instant of the first BrdU injection is equal to the percentage of the total cell cycle time ( $\left.T_{c}\right)$ spent in S-phase $\left(T_{s}\right)$, or $T_{s} / T_{c}$. This is equal to the labeling index (LI), the proportion of labeled cells in the total population at any given time $(t)$. In the experiment, the animals were killed $0.5 \mathrm{hr}$ after the initial injection; therefore, the first point on the graph is the labeling index at $t=0.5\left(\mathrm{LI}_{0.5}\right)$. In order to determine $T_{s} / T_{c}$ at $t=0$, we extrapolated the curve back to $t=0$ and determined the $\mathrm{LI}_{0}$.

Since only $T_{s} / T_{c}$ of the population are labeled by a single BrdU injection, it is necessary to make a series of injections to label the entire proliferating population. To do this, BrdU was 


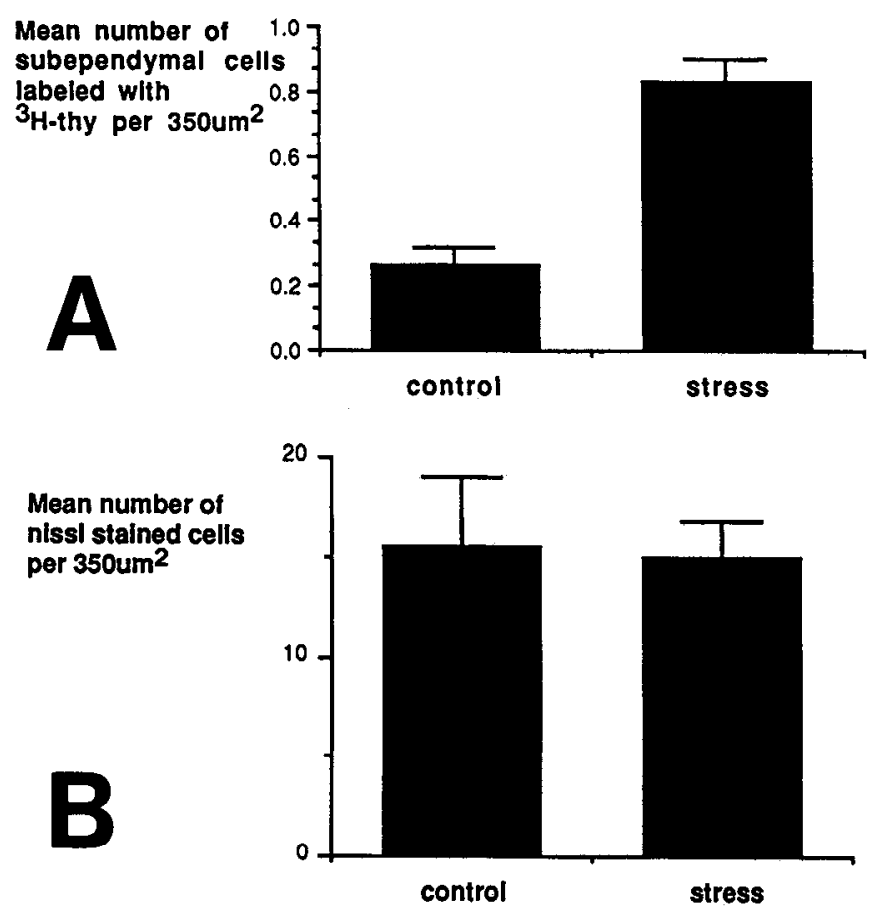

Figure 3. A, The mean number $( \pm \mathrm{SEM})$ of subependymal cells surrounding the lateral ventricles that were labeled with ${ }^{3} \mathrm{H}$-thy in control mice $(n=4)$ and mice stressed by anesthetic treatment $24 \mathrm{hr}$ earlier $(n$ $=5) . B$, The mean number $( \pm$ SEM) of Nissl-stained cells in the same areas of the subependymal layer counted in $A$ in both the control $(n=$ $4)$ and the stressed $(n-5)$ animals.

injected every hour. This ensured that the time between the injections was less than $T_{s}$, so that we would not miss cells as they passed through $S$-phase between injections.

The best-fit curve for the data from $0-8.5 \mathrm{hr}$ of BrdU labeling is a straight line ( $R$ coefficient $=0.98$ ). The line is the leastsquares fit obtained with the conditions for a one-population model. If there is more than one intermingled cell cycle population in the subependyma, then the slope of the best-fit curve for the data points will not be linear. While the best estimate indicates that a one-population model is appropriate, it remains possible that a small percentage of the proliferating population has different cell cycle kinetics.
The number of labeled cells reaches a maximum when all the proliferating cells have been labeled. The time it takes to reach this maximum is equal to $T_{c}-T_{s}$ (the time it takes a cell that was just at the end of S-phase when it was first exposed to BrdU to pass through the rest of the cell cycle and then reenter $S$ ). Not all the cells in the subependymal zone are proliferating since the maximum number of proliferating cells does not reach $100 \%$. The growth fraction (GF) is the proportion of the total population that is proliferating, and in a single population model, it is derived from the proportion of cells labeled at (or after) $T_{c}$ c $-T_{s}$. From Figure 4, we calculate that $T_{c}-T_{s}=8.5 \mathrm{hr}, \mathrm{LI}_{0}=$ $11 \%$, and $\mathrm{GF}=33 \%$. From these data we estimate that $T_{\text {c }}$ for the population $-12.7 \mathrm{hr}$ and $T_{\mathrm{s}}-4.2 \mathrm{hr}$. The proliferating population comprises $33 \%$ of the total subependymal population in the dorsolateral region of the lateral ventricle. This $33 \%$ figure may constitute the maximal proliferating population, insofar as the multiple BrdU injections in this experiment were a stress manipulation. It follows, then, that the remaining $67 \%$ of the subependymal cells make up a nondividing population of dorsolateral and subependymal cells.

The intrahilar proliferative zone in the postnatal mouse was previously examined using cumulative BrdU labeling (Nowakowski et al., 1989). In this region of the brain, the new postmitotic cells normally migrate away from the proliferative zone. To assess the potential cytotoxic effects of BrdU, Nowakowski et al. (1989) looked for pyknotic cells in the intrahilar proliferative zone. Despite the repeated administration of BrdU, no evidence of pyknosis was observed. Furthermore, at the doses used, BrdU has been shown not to affect the ability of neurons to migrate and differentiate in vivo (Miller and Nowakowski, 1988). These results make it unlikely that our cumulative labeling data reflect any cytotoxic effects of BrdU; however, given that a somewhat different dose schedule was used in the present study, we cannot completely rule out the possibility of some toxicity.

Animals that were injected with BrdU cumulatively over 5 hr, then killed 8 d later, revealed no labeled cells in the subependymal layer. Animals that were given the same BrdU treatment and killed after $2 \mathrm{~d}$ had many BrdU-labeled cells in the subependyma. We assume that these cells are proliferating and diluting out the BrdU label at $2 \mathrm{~d}$; however, the difficulty in assessing a change in the intensity of the BrdU labeling did not allow for a more quantitative analysis. The complete lack of
Figure 4. The percentages of BrdUlabeled subependymal cells $0.5 \mathrm{hr}$ after each hourly injection of BrdU for 14.0 hr. Each data point represents the mean \pm SEM of the counts obtained from two samples each from at least four animals. The percentage of BrdU-labeled cells increased linearly for $8.5 \mathrm{hr}$ from an initial value of $11 \%\left(\mathrm{LI}_{0}=11 \%\right)$ of the total number of Nissl-stained cells to a maximum value of $33 \%(\mathrm{GF}=33 \%$ ). The linear increase in the proportions of BrdU-labeled cells indicates that the proliferating cells comprise a single population in terms of the lengths of the cell cycle $\left(T_{c}=12.7 \mathrm{hr}\right)$ and the S-phase $\left(T_{s}=4.2 \mathrm{hr}\right)$. The two straight lines represent the best-fit curves for the initial $8.5 \mathrm{hr}$ and for the subsequent plateau from 8.5 to $14.0 \mathrm{hr}$.

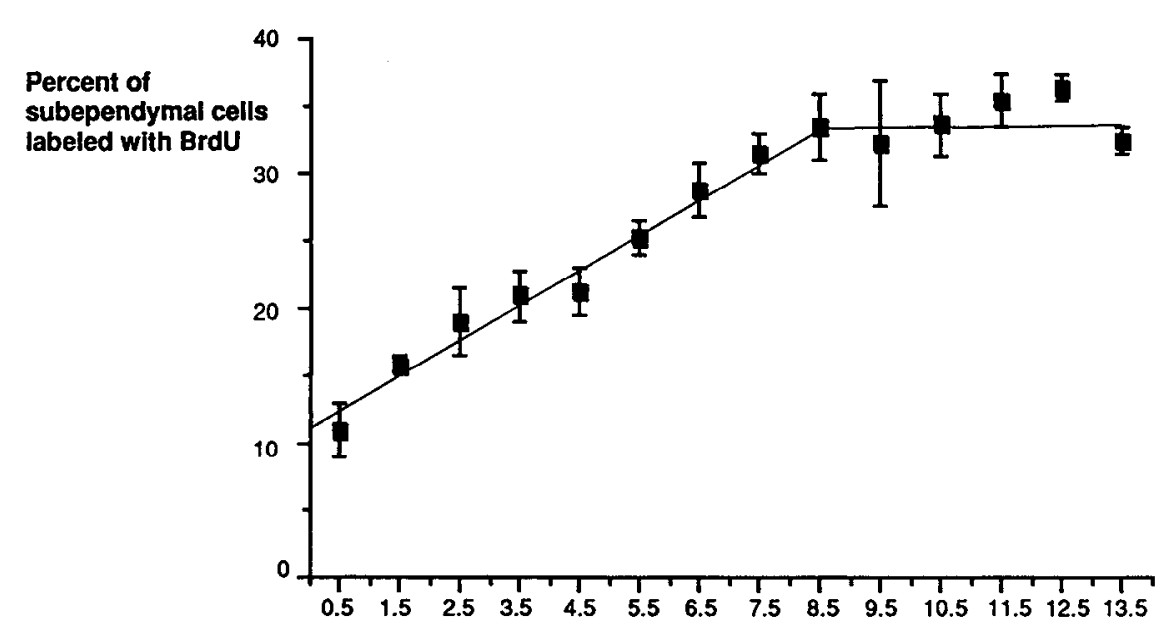

Time (in hours) after initial BrdU injection 


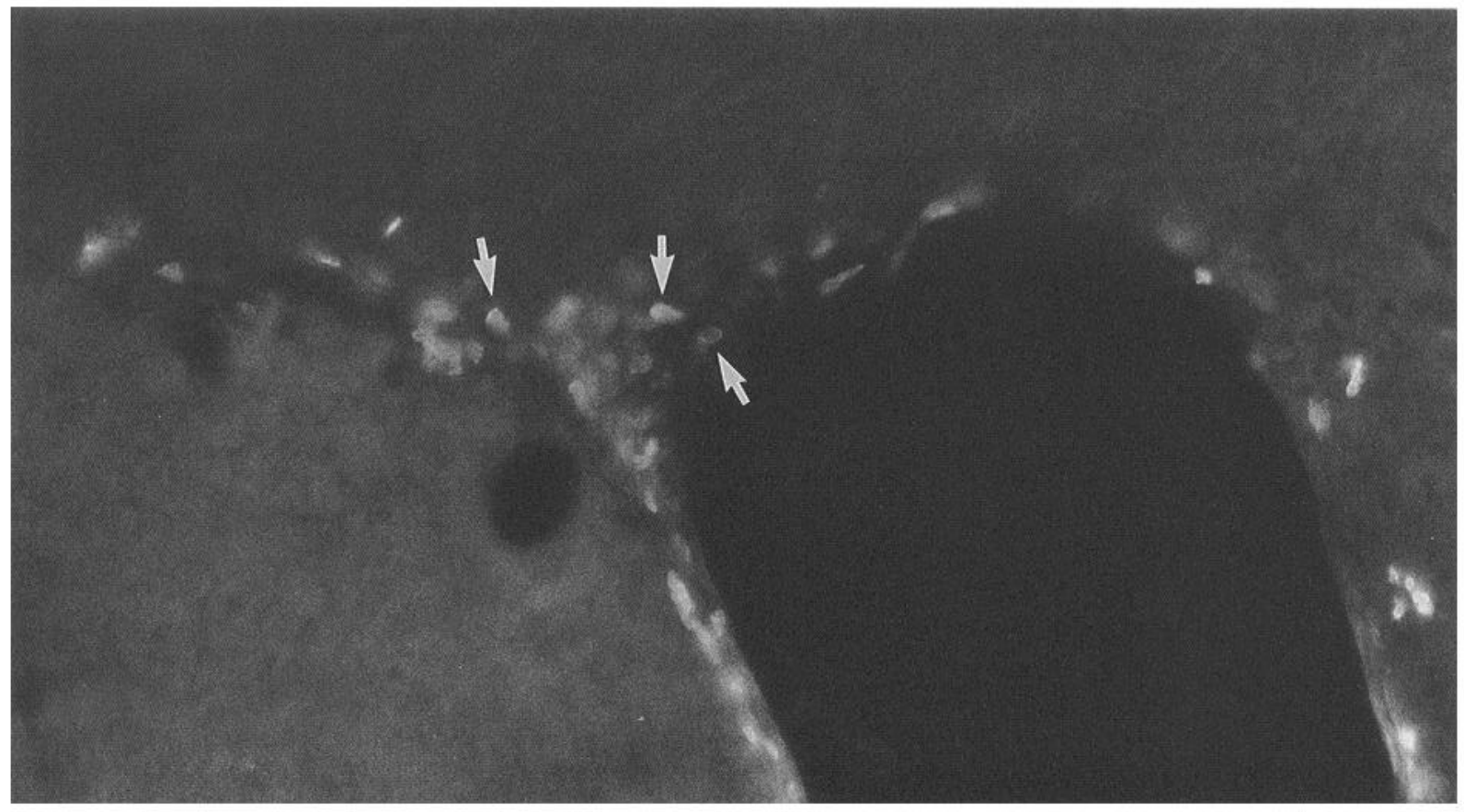

Figure 5. Fluorescence photomicrograph of the dorsolateral region of the lateral ventricle in an animal continuously exposed to BrdU (65 mg/ kg, i.p.) through hourly injections. Arrows point to examples of BrdU-labeled subependymal cells $10.5 \mathrm{hr}$ after the initial BrdU injection, a time when the maximum percentage (33\%) of labeled cells is reached.

BrdU labeling by $8 \mathrm{~d}$ suggests that cells are not undergoing mitosis once and then entering into a long postmitotic period, but are instead continuing to proliferate (hence diluting the label by $8 \mathrm{~d}$ ). Since the size of the subependymal layer remains constant in the adult animal, the progeny of the proliferating cells must either migrate away from the ventricle into the surrounding tissue or undergo cell death. We were able to test these possibilities by using recombinant retrovirus injections and examining the size of the labeled clones and the location of the labeled progeny.

\section{Clone size does not vary with survival time}

Retroviral injections into adult animals resulted in the same clone size regardless of the time of death postinjection. At 10 hr ( $n=7,42$ clones), $1 \mathrm{~d}(n=6,12$ clones), $2 \mathrm{~d}(n=10,23$ clones), and $8 \mathrm{~d}$ ( $n=9,30$ clones) postinjection, the majority of clones contained one or two cells (Figs. 6, 7). Indeed, over $60 \%$ of these one- or two-cell clones were one-cell clones. There was no significant interaction between the number of clones in each of the size categories ( 1 or 2 cells/clone vs. 3 or 4 cells/ clone vs. $>4$ cells/clone) and the various survival times examined $\left(F_{3.28}=0.19 ; p>0.05\right)$. Thus, the number of cells per clone did not vary over the survival times. There was also no significant interaction between the number of clones per brain and the different survival times $\left(F_{3.28}=1.57 ; p>0.05\right)$. Thus, the number of clones per brain did not change significantly over time.

All of the clones were confined to the subependymal layer regardless of the time postinjection. Groups of cells were often observed on opposite sides of the ventricle (i.e., medial vs. lateral) in a given animal. We concluded that these groups were separate clones. Based on the distributions of lacZ-positive cells surrounding the ventricle, we concluded that each cell within a single clone was no greater than $100 \mu \mathrm{m}$ from its nearest lacZ- labeled neighbor in any direction. Increasing the accepted distance between neighboring labeled cells within an individual clone from 100 to $200 \mu \mathrm{m}$ did not significantly alter the distribution of clone sizes over time $\left(F_{6,56}=0.7 ; p>0.05\right)$. Thus, there was no significant difference in the number of cells per clone over the various survival times regardless of whether the accepted distance between the labeled cells for defining a clone was 100 or $200 \mu \mathrm{m}$. This suggests that the original definition of a clone $(<100 \mu \mathrm{m}$ between labeled cells) was capturing for the most part the progeny of a single infected cell. Most important, individual animals that only contained single clones $(n=4)$ did not have clones greater than two cells in size, and the cells of these two cell clones were never more than $100 \mu \mathrm{m}$ apart. Even in two brains with a large number of clones (14 and 19 clones, respectively), the vast majority ( $>85 \%)$ of the clones were one

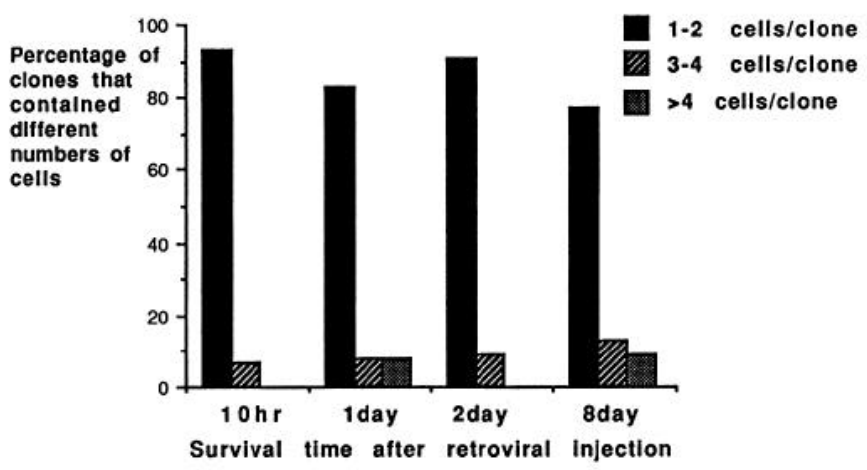

Figure 6. The percentages of the clones that were one or two cells, three or four cells, or five or more cells in size at $10 \mathrm{hr}, 1 \mathrm{~d}, 2 \mathrm{~d}$, and $8 \mathrm{~d}$ after lateral ventricle injections of a replicant-deficient, recombinant retrovirus. Data represent the percentage of clones of each size at each of the survival times. 


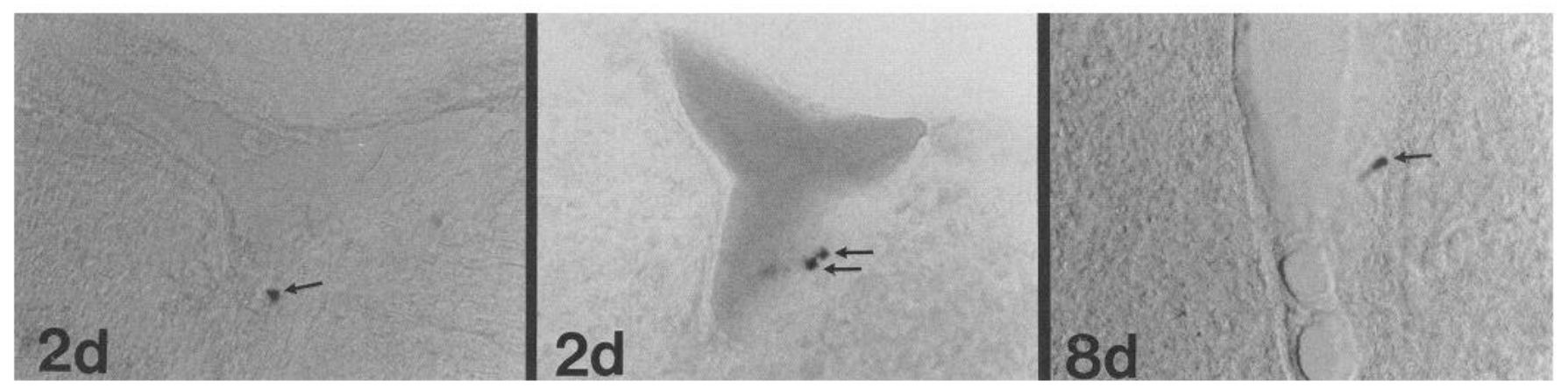

Figure 7. Bright-field photomicrographs showing retrovirally labeled cells (arrows) in the subependyma at 2 d [a 1 cell clone (left) and a 2 cell clone (middle)] and $8 \mathrm{~d}$ [a 1 cell clone (right)]. The out-of-focus staining in the middle panel is an artifact, and the out-of-focus staining in the right panel is a cell process, not the staining of a separate cell body. The clones were confined to the subependymal layer and were not observed in the surrounding tissue of the adult brain.

or two cells in size. Again, this suggests that the original distance definition of a clone was capturing primarily the distribution of the descendents of single infected cells.

Retrovirally labeled cells were sometimes observed along the injection tract in the cortex of infected animals. The labeled cells appeared in clusters along the injection tract in some of the cases at all of the survival times examined. These lacZlabeled cells in the cortex were never spatially contiguous with labeled subependymal cells. The size of the clusters did not vary over time, although the morphology of the cells did change with longer survival times. After $10 \mathrm{hr}$ survival the cells along the injection track had no processes, but after $8 \mathrm{~d}$ many of the cells had processes. We suggest that the labeled cells in the cortex are the result of simultaneous retroviral uptake by individual cells induced to proliferate by injury, rather than a group of clonally related cells from a single infection. These injury-induced, proliferating cells are most likely astrocytes and/or microglia (Korr et al., 1973; Lindsay, 1986; Graeber et al., 1988; Morshead and van der Kooy, 1990).

Due to our estimation of $T_{c}=12.7 \mathrm{hr}$, it should be noted that at $10 \mathrm{hr}$ postlesion it would be impossible to have a clone of three or more cells. From Figure 6 it can be seen that $7 \%$ of the clones fall into this category at $10 \mathrm{hr}$. We hypothesize that this $7 \%$ represents the probability of double infection with the retrovirus (i.e., more than one infected cell making up what we have defined as a clone). This, therefore, should provide a good estimate of the rate of double infections at all the survival times examined. By $24 \mathrm{hr}$, it would likewise be impossible to have a clone of more than four cells with a $T_{c}$ of $12.7 \mathrm{hr}$. Hence, we hypothesize this clone ( 1 of 12 observed) represents a double infection.

The retroviral lineage study reveals that the surviving progeny of the proliferating progenitors remain confined to the subependyma and do not migrate into the surrounding tissue. Combined with the finding that $8 \mathrm{~d}$ after BrdU was injected (hourly injections for $5 \mathrm{hr}$ ) there were no labeled cells in the subependyma, we suggest that the proliferating subependymal cells continue to divide in the subependymal layer (hence diluting the BrdU label) and must undergo some cell death there. Because the vast majority of clones are one or two cells in size, the proliferating population must be dividing in a steady-state mode whereby a stem cell divides and the postmitotic progeny undergo cell death.

Examining the distributions of the numbers of cells per clone at longer survival times, it is apparent that the rate of double infection (approximately $7 \%$ ) may not account for the somewhat increased frequency of larger clones $(3$ or 4 cells or $>4$ cells per clone) at these longer survival times. Perhaps a minority of the proliferating population divides and differentiates (dies) with different kinetics. For instance, if the death of some postmitotic progeny occurred longer than $12.7 \mathrm{hr}\left(T_{c}\right)$ after the last division, then a few larger clones would result. It is also possible that in a minority of cases, both progeny of a single division die in the subependymal zone. The mean number of clones per brain was larger after $10 \mathrm{hr}$ (mean of 6 clones per brain) than after $1 \mathrm{~d}$ (mean of 1.6 clones per brain) survival, although this difference did not reach statistical significance $\left(t_{11}=0.09 ; p>0.05\right)$. The larger mean number of clones per brain at $10 \mathrm{hr}$ was primarily due to two animals with many clones. This variation in the number of clones per brain may hint at the death of both progeny after mitosis in some cases. If this does occur, then the few larger clones that were seen at $8 \mathrm{~d}$ may allow for the consistent replacement of subependymal cells that must be necessary to maintain the constant size of the adult subependymal layer.

We can make an estimate of the usual time between proliferation and the death of the postmitotic progeny by noting that at all times of death after retroviral injection, the vast majority of clones are one or two cells in size. This implies that before individual labeled stem cells go through S-phase and mitosis for a second time, the postmitotic progeny must have undergone cell death (i.e., within $12.7 \mathrm{hr}$ ). Thus, there was no increase in the number of three-cell clones after 1 and $2 \mathrm{~d}$ survival times, despite the fact that the dividing cells continue to be mitotically active.

\section{Discussion}

In the postnatal period, the subependymal layer of the rodent forebrain appears as a collection of undifferentiated, mitotically active cells separated from the lumen of the ventricle by a single row of ependymal cells bordering the lateral ventricles. Mitotic activity within the subependymal layer has been consistently reported in postnatal tissue, and it appears to persist throughout adult life (Smart, 1961; Altman, 1963, 1969; Hopewell, 1971). We have used continuous BrdU labeling to examine the proliferation kinetics of these subependymal cells in adult mice. The most actively proliferating region surrounding the lateral ventricle is the dorsolateral corner, with a growth fraction of $33 \%$, suggesting that one-third of the cells make up the proliferating portion of the subependymal population in this region. The estimated cell cycle time $\left(T_{c}\right)$ for these dividing cells is 12.7 $\mathrm{hr}$, with an S-phase $\left(T_{s}\right)$ of approximately $4.2 \mathrm{hr}$. Previous stud- 
ies in adult rat tissue have used cumulative ${ }^{3} \mathrm{H}$-thy experiments to label proliferating subependymal cells and have derived values of $T_{c}=18-21 \mathrm{hr}$ and $T_{s}=8.5-12.3 \mathrm{hr}$, with estimates of the growth fraction varying between $16 \%$ and $35 \%$ (Lewis, 1968; Lewis et al., 1977; Schultze and Korr, 1981). The differences may be due to the different regions of the subependymal layer examined and to the different species studied. We studied the most mitotically active subependymal region of the adult mouse brain, the dorsolateral region. The growth fraction would have been considerably less had we derived our estimates from the subependyma surrounding the entire ventricle.

The retroviral lineage tracing data reveal that the number of cells per clone (the majority are 1 or 2 cell clones) does not change regardless of the survival time postinfection, and that the labeled cells are always confined to the subependymal zone. Moreover, cumulatively injecting the animals with BrdU over $5 \mathrm{hr}$, then allowing an $8 \mathrm{~d}$ survival time, revealed no labeled cells in the subependyma. This implies that the cells labeled on day 0 do not enter into an extended nonmitotic phase, but continue to divide and dilute the label. Taken together, these data suggest a steady-state mode of subependymal cell proliferation. A single labeled cell divides, and the postmitotic progeny undergoes cell death (hence the clone size remains constant). The remaining progeny goes on to divide again (hence diluting the label), and the one postmitotic cell will once more undergo cell death, repeating the cycle. The observation that the clone size remains the samc over time gives an indication of the maximum time that the postmitotic progeny of each division can survive. Since there is no increase in the relative frequency of three-cell clones after 1 or $2 \mathrm{~d}$ survival, the postmitotic progeny must be dying before the stem cell goes through mitosis for a second time. From the cumulative labeling study, it follows that the one postmitotic cell from each division must die within $12.7 \mathrm{hr}\left(T_{c}\right)$.

It has been generally assumed that new postmitotic subependymal cells migrate out of the subependymal layer to replace degenerating glial cells (Altman, 1966; Lewis, 1968; Privat and Leblond, 1972; Paterson et al., 1973) or to become neurons (Altman, 1969). This assumption is partially based on the observation that following a single ${ }^{3} \mathrm{H}$-thy injection there is the exponential decline of the mean grain count per subependymal nucleus as a function of time, indicating continuous division of labeled cells. However, despite this continuous cell division, the number of cells in the subependymal layer does not increase with time (Hopewell, 1971; present results). Labeled glial cells and neurons in the regions bordering the ventricles and in the surrounding tissue have been identified after postnatal ${ }^{3} \mathrm{H}$-thy injections (Altman, 1962, 1963; Privat and Leblond, 1972; Korr et al., 1973). These observations were interpreted as indicating that the postmitotic progeny migrate away from the subependymal layer and differentiate into glia or neurons. We tested this hypothesis using retroviral injections into the lateral ventricles to label proliferating subependymal cells, and studying the distributions of labeled cells up to $8 \mathrm{~d}$ later. We failed to substantiate the hypothesis. Serial sections of the brain revealed no retrovirally labeled cells in the brain tissue outside of the subependymal layer. Indeed, the only non-subependymal, retrovirally labeled cells were the few, presumably injury-induced, proliferating cells along the retroviral injection track in the cortex. These injection tract cells were not contiguous with the labeled cells in the subependymal layer at any time examined postinfection. We suggest that under normal conditions the su- bependymal cells do not migrate, or differentiate into glia or neurons. Smart (1961) also concluded that the proliferating subependymal cells ultimately degenerate within the layer, after finding large numbers of pyknotic subependymal cells in the adult animal. It seems likely that the few ${ }^{3} \mathrm{H}$-thy-labeled cells outside of the subependyma that led to the initial replacement hypothesis are indicative of normally occurring, but minor, proliferation in adult brain tissue outside of the subependyma (Altman, 1963; Korr, 1980).

The adult subependymal layer contains actively proliferating cells, yct we can only speculate on the function of thesc cells. In adult birds, the ventricular zone contains cells that continue to proliferate and migrate out into the regions of the brain important for song production (Alvarez-Buylla et al., 1990; Nordeen and Nordeen, 1990). The mammalian subependymal zone has been described as a "degenerate remnant" of the embryonic ventricular zone (Smart, 1961). While we have no evidence for any functional differentiation of these proliferating subependymal cells, it appears that their mitotic activity can be regulated. It was possible to induce three times the number of ${ }^{3} \mathrm{H}$ thy-labeled subependymal cells $24 \mathrm{hr}$ after stressing mice. This ability to manipulate the cells suggests that the proliferating subependymal cells may serve some function in the adult brain or, minimally, that they are still responsive to stimuli that influence the cell cycle. We do not know whether stress affects the cells by decreasing $T_{c}$ (and hence we observe more cells after a single BrdU injection) or whether the stress recruits subependymal cells that do not normally comprise the proliferating population. Stress could also prevent some of the stem cells from dying and/or extend the survival time of the postmitotic progeny.

One possible function that could be attributed to the proliferating subependymal cells is that they serve as a reserve source of undifferentiated cells in case of damage to brain tissue. To examine this possibility, a neurotoxin (kainic acid) was injected unilaterally into the adult striatum at the same time that the recombinant retrovirus was injected into the ipsilateral lateral ventricle. The brain tissue was examined $6 \mathrm{~d}$ later, at the time of maximum gliosis within the striatum (Morshead and van der Kooy, 1990) to determine if any retrovirally labeled cells appeared in the striatum surrounding the lesion. Preliminary findings revealed that the retrovirally labeled subependymal cells were still confined to the subependymal layer and did not differentiate into glial cells or migrate into the nearby striatal tissue (C. M. Morshead and D. van der Kooy, unpublished observations). It remains possible that the proliferating subependymal cells have the potential to take on a particular striatal phenotype, but have not yet been exposed to the appropriate inducing stimuli. It would be interesting to examine further the potential of these proliferating subependymal cells by exposing them to different environments, for example, by transplanting them to different regions of the adult brain or to an earlier time in development.

\section{References}

Altman J (1962) Are neurons formed in the brains of adult mammals? Science 135:1127-1128.

Altman J (1963) Autoradiographic investigation of cell proliferation in brains of rats and cats. Anat Rec 145:573-591.

Altman J (1966) Proliferation and migration of undifferentiated precursor cells in the rat during postnatal gliogenesis. Exp Neurol 16: 263-278.

Altman J (1969) Autoradiographic and histological studies of postnatal 
neurogenesis. IV. Cell proliferation and migration in the anterior forebrain, with special reference to persisting neurogenesis in the olfactory bulb. J Comp Neurol 137:433-457.

Alvarez-Buylla A, Theelen M, Nottebohm F (1990) Proliferation "hot spots" in adult avian ventricular zone reveal radial cell division. Neuron 5:101-109.

Bayer SA, Altman J, Russo R (1990) Lateral migration of cells in embryonic neocortex. Soc Neurosci Abstr 16:803.

Graeber MB, Tetzlaff W, Streit WJ, Kreutzberg G (1988) Microglial cells but not astrocytes undergo mitosis following rat facial nerve axotomy. Neurosci Lett 85:317-321.

Hopewell JW (1971) A quantitative study on the mitotic activity in the subependymal plate of adult rats. Cell Tissue Kinet 4:273-278.

Korr H (1980) Proliferation of different cell types in the brain. Adv Anat Embryol Cell Biol 61:1-69.

Korr H, Schultze B, Maurer W (1973) Autoradiographic investigations of glial proliferation in the brains of adult mice. I. The DNA synthesis phase of neuroglia and endothelial cells. J Comp Neurol 160:477490.

Lewis PD (1968) A quantitative study of cell proliferation in the subependymal layer of the adult rat brain. Exp Neurol 20:203-207.

Lewis PD, Patel AJ, Balazs R (1977) Effect of undernutrition on cell generation in the adult rat brain. Brain Res 138:511-519.

Lindsay RM (1986) Reactive gliosis. In: Astrocytes, Vol III (Federoff S, Vernadakis A, eds), pp 231-262. London: Academic.

Miller MW, Nowakowski RS (1988) Use of bromodeoxyuridine-immunohistochemistry to examine the proliferation, migration and time of origin of cells in the central nervous system. Brain Res 457:44-52.

Morshead C, van der Kooy D (1990) Separate blood and brain origins of proliferating cells during gliosis in adult brains. Brain Res 535: 237-244.
Nordeen EJ, Nordeen KW (1990) Neurogenesis and sensitive periods in avian song learning. Trends Neurosci 13:31-36.

Nowakowski RS, Lewin SB, Miller MW (1989) Bromodeoxyuridine immunohistochemical determination of the lengths of the cell cycle and the DNA-synthetic phase for an anatomically defined population. J Neurocytol 18:311-318.

Packard DS, Menzies RA, Skalko RG (1973) Incorporation of thymidine and its analog, bromodeoxyuridine, into embryos and maternal tissues of the mouse. Differentiation 1:397-405.

Paterson JA, Privat A, Ling EA, Leblond CP (1973) Investigation of glial cells in semithin section. III. Transformations of subependymal cells into glial cells shown by radioautography after ${ }^{3} \mathrm{H}$-thymidine injection into the lateral ventricle of the brain of young rats. J Comp Neurol 149:83-102.

Privat A, Leblond CP (1972) The subependymal layer and neighbouring region in the brain of the young rat. J Comp Neurol 146: 277-302.

Schultze B, Korr H (1981) Cell kinetic studies of different cell types in the developing and adult brain of the rat and the mouse: a review. Cell Tissue Kinet 14:309-325.

Smart I (1961) The subependymal layer of the mouse brain and its cell production as shown by radioautography after thymidine- $\mathrm{H}^{3}$ injection. J Comp Neurol 116:325-338.

Waechter RV, Jaensch B (1972) Generation times of the matrix cells during embryonic brain development: an autoradiographic study in rats. Brain Res 46:235-250.

Walsh C, Cepko CL (1988) Clonally related cortical cells show several migration patterns. Science 241:1342-1345. 